\title{
Thawing the Frozen Shoulder
}

\author{
Duncan C. McKeever MD, FACS CORR 1958;11:168-176
}

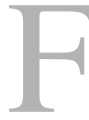

rozen shoulder has always been an enigma. According to DePalma [1], Duplay [2] in 1896 first noted the role of extraarticular tissues as the cause of frozen shoulder, and coined the term "periarthritis." DePalma (in an article reproduced in this issue) later emphasized the diffuse nature of the inflammatory changes in the tissues. McKeever, in his article "Thawing the Frozen Shoulder," published in CORR in 1958 [4], well described the syndrome and commented, "The term frozen shoulder is not a scientific one, yet it is so clearly descriptive of the condition to which it is applied that every doctor who has ever seen a case immediately recognizes the symptom complex it designates." Although generally treated as a local disorder, McKeever did not believe it was a strictly local phenomenon, and rather suggested it was a generalized disorder: "The broader concept that the frozen shoulder is a local manifestation of a general metabolic state can lead one to much more rational treatment...The etiologic concept applicable to this condition is equally applicable to all the manifestations of degenerative change in the aging or ill body...The so-called frozen shoulder is a local manifestation of a general metabolic fault." $\mathrm{He}$ believed it occurred in individuals in a general catabolic state and therefore a key principle of treatment included changing the state of metabolism to an anabolic one. He believed patients must have an adequate and balanced supply of proteins and minerals and vitamins, using protein supplements when necessary. Androgenic or estrogenic steroids or thyroid hormones, when deficient, needed to be provided.

McKeever noted the uniqueness of the shoulder, stating it was "the only joint in the body that remains almost 100 per cent of the time at or near one of its extremes of motion and passes to the other extreme rarely." This, he implied, related to immobility at the extreme where it typically resided. Physiotherapy was of paramount importance, and included restoration of abnormal posture when present. He recommended regular supervised assisted and voluntary restoration of motion and muscle strength, but not more than three times a week. With his specific regimen he stated that in patients with only moderate restriction of motion and a duration of symptoms of 1 to 3 months, a full and pain-free range of motion could be restored in 10 days to 3 weeks; the most resistant cases took up to 3 months.

He commented, "If this concept (that frozen shoulder was a local manifestation of a systemic disorder) is understood thoroughly and the treatment conceived as a result of it is carried out meticulously, frozen shoulder ceases to be a problem, and its therapy, which formerly required many months, can be completed and the patient restored to full pain-free function within a period ranging from a few days in cases of short duration to from 6-8 weeks in the most severe and prolonged cases."

Frozen shoulder remains a problem, and I have been unable to identify further work supporting McKeever's hypothesis that frozen shoulder occurs in the presence of a general catabolic state and restoration of an anabolic state is key to rapid recovery. However, there is some evidence frozen shoulder occurs more frequently in diabetics $[3,6]$, and further evidence to suggest growth factors (VEGF) are increased in the shoulders of diabetic patients with frozen shoulder, leading to increased vascularity in association with inflammation [5]. Whether these findings can be generalized to McKeever's hypothesis is unknown, but given the continuing problem of the frozen shoulder, might be a fruitful line of research.

Richard A. Brand MD Editor-in-Chief Clinical Orthopaedics and Related Research

\section{References}

1. DePalma AF. Surgery of the Shoulder. Philadelphia, PA: JB Lippincott; 1950. 


\section{Years Ago in CORR}

2. Duplay S. De la periarthrite scapulohumerale. Rev frat $d$ trav de med. 1896;53:226.

3. Fisher L, Kurtz A, Shipley M. Association between cheiroarthropathy and frozen shoulder in patients with insulin-dependent diabetes mellitus. $\mathrm{Br} J$ Rheumatol. 1986;25:141-146.

4. McKeever DC. Thawing the frozen shoulder. Clin Orthop Relat Res. 1958;11:168-176.
5. Ryu JD, Kirpalani PA, Kim JM, Nam $\mathrm{KH}$, Han CW, Han SH. Expression of vascular endothelial growth factor and angiogenesis in the diabetic frozen shoulder. J Shoulder Elbow Surg. 2006;15:679-685.

6. Thomas SJ, McDougall C, Brown ID, Jaberoo MC, Stearns A, Ashraf R, Fisher M, Kelly IG. Prevalence of symptoms and signs of shoulder problems in people with diabetes mellitus. J Shoulder Elbow Surg. 2007;16:748-751.

50 Years Ago in CORR:

Thawing the Frozen Shoulder Duncan C. McKeever MD, FACS

Richard A. Brand MD 